\title{
COSTS OF HOME CARE FOR ADVANCED BREAST AND CERVICAL CANCER IN RELATION TO COST-EFFECTIVENESS OF SCREENING
}

\author{
Marc A. Koopmanschap,' B. Martin van Ineveld ${ }^{2}$ and Theo E. M. Miltenburg ${ }^{3}$ \\ 'Department of Public Health and Social Medicine, 'Institute for Medical Technology Assessment, \\ Erasmus University Rotterdam, The Netherlands, and ${ }^{3}$ Institute for Applied Social Sciences, Nijmegen, \\ The Netherlands
}

\begin{abstract}
The costs of home care in the Netherlands are estimated for women with advanced breast and cervical cancer. We observe a growing role of intensive home care for the terminally ill patients. The average costs of home care are df 8500 per patient for breast cancer patients and df 7200 for cervical cancer patients. More than half of these costs are incurred in the last month before death. The level of home care in the preceding months is quite modest (df 120 per month for both diseases), not taking into account informal care. The costs of home care for patients with advanced cancer are only slightly related to the site of the primary tumor from which the metastases originate. Total average costs per patient during advanced disease, including hospital and nursing home care, amount to $\mathrm{dfl} 42,700$ for breast cancer and $\mathrm{dfl} 29,000$ for cervical cancer. This difference in costs is largely attributable to the longer duration of advanced disease for breast cancer, which substantially affects hospital costs. The high costs of care to patients with advanced cancer contribute to a favourable cost-effectiveness ratio of those screening programmes which reduce mortality and consequently the costs of care to advanced cancer patients.
\end{abstract}

Key words-homecare, cancer, costs, cost-effectiveness, breast cancer, cervical cancer

\section{INTRODUCTION}

In this article we estimate the costs of home care in the Netherlands for patients with advanced breast or cervical cancer. The role of home care in treating cancer is becoming more important in the Netherlands, but so far a reliable estimate of the costs of home care per patient is lacking internationally.

Data on home care related to patient characteristics as age, sex and diagnosis are scarce for the Netherlands. Recently, detailed data became available on intensive home care in three Dutch regions for patients in the terminal phase of disease [1]. Combined with information of other surveys concerning home care we derived a global estimate of the total costs of home care during the period of advanced disease. During this period, women can stay alternatively at home, in a hospital or in a nursing home. Staying at home the patient may receive professional and/or informal care. Professional care in the Netherlands is mainly delivered by district-nurses, home helps, general practitioners and private nurses. Informal care is defined as care provided by relatives, neighbours, friends and volunteers.

Although the amount of care varies considerably between individual women with cancer, in general the intensity of home care is low at the start of the period of advanced disease and initially increases only gradually. The level of care rises rapidly in the last months before death and remains high. This care pattern also holds for hospital care [2-5].
First, we estimated the costs of home care for advanced disease, taking into account the role of professional as well as informal care. These costs were combined with information on the costs of hospital and nursing home care to arrive at the total costs for patients with advanced breast and cervical cancer.

Finally, the results were used to illustrate the sensitivity of cost-effectiveness ratios of screcning for breast and cervical cancer to variation in the costs of care to patients with advanced cancer.

\section{MATERIALS AND METHODS}

The advanced stage of breast and cervical cancer is defined here as starting when metastasis or recurrence of the tumor are clinically detected and terminating when the patient dies. The length of the period of advanced disease was estimated by a detailed analysis of hospital files of 68 women having advanced breast cancer and 35 women with advanced cervical cancer. The average length of advanced cancer was estimated at 21 months for breast cancer and 11 months for cervical cancer $[6,7]$.

As stated before initially the level of home care will be relatively low, in general, but it will rise rapidly in the last months before dying. Figure $l$ illustrates this pattern. The total amount of home care provided is represented by the area under the solid line in Fig. 1 . It could be calculated using exact data on care for each patient over the entire course of advanced disease. The amount of care can be approximated by 


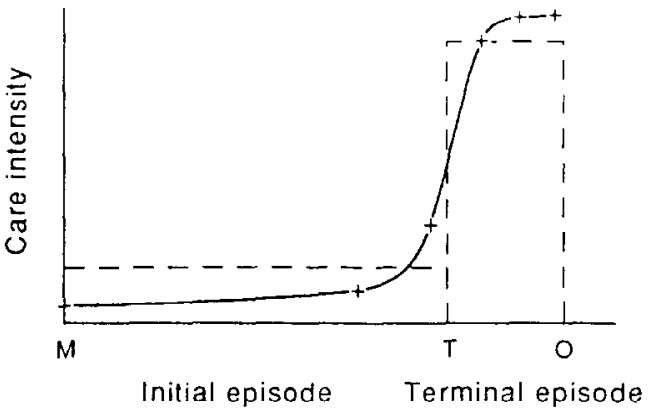

Fig. 1. Illustration of the pattern of home care for women with advanced cervical cancer.

summing the estimated amount of care in each episode, as illustrated by the areas under the dashed lines in Fig. 1. The available data enabled us to discern two episodes, the initial episode $(\mathrm{M}-\mathrm{T})$ and the terminal episode $(\mathrm{T}-\mathrm{O})$.

Our definition of the term 'terminal episode' originates from the Dutch Intensive Homecare Project. In this project care is provided up to a maximum of 3 months. The 'initial episode' consequently is defined as the time-span before the terminal episode.

In order to calculate the total costs of home care we estimated for each episode and for each type of care the following variables: the length of the episode, the proportion of patients receiving home care, the care-intensity and the costs per unit of care. Table 1 provides an overview of the Dutch studies on home care, which were used to estimate the costs of home care for advanced breast and cervical cancer.

The terminal episode will be discussed first.

\section{Terminal episode}

The Intensive Homecare Project (IHP), since 1987 in the Netherlands operating in an experimental setting in three regions: Amsterdam, West-Brabant/ Zeeuws Vlaanderen and Groningen, covering 13\% of the population (see Table 1), provided data about intensive home-care for terminally ill patients in 1988 [1]. This project aims at patients who would otherwise be in need of hospital or nursing home care and for whom informal care is available $(62 \%$ of the patients have advanced cancer). The amount of professional and informal care provided was registered daily.

We used data for 1988 about intensive home care for 67 patients having advanced breast cancer and 32 patients with advanced cancer of the female genital organs (cervical cancer was not discerned as a separate diagnosis). The number of female cancer patients in the study period was 294 . As Table 1 shows, the age-distribution of the women with breast cancer and all cancers together was very alike. Women having cancer of the female genital organs were on average slightly older.

A substantial part of terminally ill patients staying at home only received 'regular' home-care which is less intensive than the IHP-care. We used two data

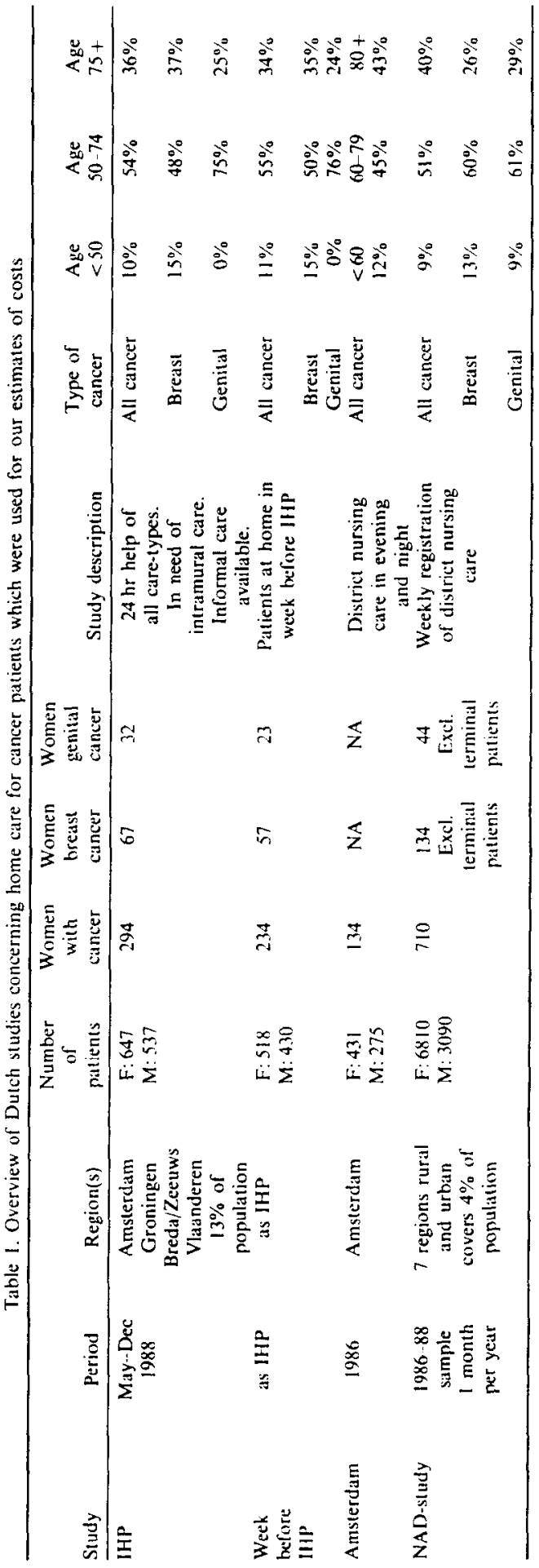


sources to calculate the amount of 'regular' home care: a study of district nursing care in the evening and night for 134 women with cancer in the city of Amsterdam and data about the level of regular care for 80 patients with breast and female genital cancer in the last week before entering the IHP $[8,9]$, see Table 1 for details on the surveys. The care-intensity for these two groups appeared to be remarkably similar.

\section{Initial episode}

Data about home-care in the initial episode are scarce. Representative samples taken in 1986, 1987 and 1988 by the National Association of Districtnursing provided data for 10,000 patients on the amount of district nursing in seven rural and urban regions during one month each year, see Table 1 [14]. The amount and type of care and patients characteristics are registered in detail by district nurses. We pooled the data from the three samples, because there were no large differences in design and outcomes.

Again the patients selected were women with breast cancer and cancer of the female genital tract as main diagnosis. Women labelled by the nurses as terminal patients in this registration were excluded from the sample, resulting in 134 women with breast cancer and 35 with female genital cancer in the period 1986-1988. The age-distribution of these women is comparable to the women receiving intensive home care, see Table 1.

We used the average number of patients per sample receiving district nursing care and the care-intensity found as estimates for the average amount of district nursing in the initial episode.

National data about home help only provide information about the average level of care by agegroup [10]. Additional research at one home help agency revealed more diagnosis-specific information [11]. Data on care supplied by general practitioners, private nurses and informal care were not available for the initial period.

Costs per hour of care for the relevant types of professional care were calculated for the year 1990 , taking into account the relation between patient time and total working time, the costs of indirect personnel, allowances for work beyond office hours and costs of nursing equipment [10, 12-14]. Informal care has also been valued. According to economic theory, two valuation methods can be used: the opportunity cost method and the market value approach. The first assesses the individual value of the time sacrificed by the care provider. An estimate of this value requires very detailed data on the preferences of informal care suppliers. Using the actual amount of care provided by informal care suppliers to determine the value of time invested may lead to biased estimates. If the informal care supplier is completely free in choosing the amount of care the value of time sacrificed could be estimated. The often limited availability of professional care may induce informal care suppliers to provide more care than they would supply if they were free to choose. which can easily lead to underestimating the value (and costs) of informal care [15].

Instead we used the market value approach valuing the costs of informal care from a more social point of view [16]. The price of professional care is used as the shadow-price for informal care reasoning that if informal care is not available, it has to be substituted by professional care. On average informal care providers will have a lower productivity than professionals and they will carry out more easy tasks. We roughly corrected for this by using the costs of the cheapest type of home help which closely resemble the market price of household services.

\section{RESULTS}

\section{Terminal episode, intensive home care}

Length of episude. Sixty-seven women having advanced breast cancer as well as 32 women with metastases of cancer of the female genital tract received on average 3 weeks of intensive home-care in the IHP. This 3-week period applies also to the total group of 294 female cancer patients. The variance in episode length is considerable (see standard deviation). The distribution is highly skewed to the left as indicated by the value of the median which is small compared to the mean. This pattern holds for all variables estimated, but it is a quite common phenomenon in health care consumption: many 'modest' consumers and relatively few 'large' consumers.

Proportion of women receiting care. Assuming nationwide coverage of the intensive home care programme, which by now is being effectuated and taking into account the number of breast and cervical cancer deaths per year gives an estimation of $30 \%$ and $27 \%$ respectively of the terminal patients receiving intensive home care (see Tables $2 \mathrm{a}$ and $\mathrm{b}$ ). Only a small minority of these women did not die at home, but went to a hospital or nursing home after receiving home care, for which we corrected.

Care intensity. On average the breast cancer patients received $34 \mathrm{hr}$ district nursing per week, $16 \mathrm{hr}$ home help, 11 hours private nursing, $1.5 \mathrm{hr}$ GP care and $45 \mathrm{hr}$ informal care (Table $2 \mathrm{a}$ ). For cancer of the female genital tract the figures were similar (see Table $2 b$ ). The amount of care provided by physiotherapists and social workers turns out to be negligible. IHPdata and international literature indicate that in case of advanced cancer the site from which metastases originate does not significantly influence the amount of care and costs $[2,5,12,17]$.

Costs per hour of care. The costs per hour for district nursing are significantly higher than for home help. The costs per hour for general practitioners are the highest, but the amount of care is quite modest. 
Table 2(a). Estimates for length, participation and intensity of home care for breast cancer pattents having advanced disease, average values (medians and standard deviations in parentheses)

\begin{tabular}{|c|c|c|c|}
\hline & \multirow[b]{2}{*}{ Initial episode } & \multicolumn{2}{|c|}{ Terminal episode } \\
\hline & & Intensive care & Regular care \\
\hline $\begin{array}{l}\text { Variable } \\
\text { Episode length }\end{array}$ & $\begin{array}{c}\text { Average (median, SD) } \\
20(19,16) \text { months }\end{array}$ & $\begin{array}{l}\text { Average (median, SD) } \\
22(9.28) \text { days }\end{array}$ & $\begin{array}{c}\text { Average (median, SD) } \\
22(9.28) \text { days }\end{array}$ \\
\hline \multicolumn{4}{|c|}{ Proportion of patients receuing home care } \\
\hline $\begin{array}{l}\text { District nursing } \\
\text { Home help }\end{array}$ & $\begin{array}{l}22 \% * \text { each month } \\
10 \% * \text { each month }\end{array}$ & $\begin{array}{l}30 \% * * \\
30 \% * *\end{array}$ & $\begin{array}{l}20 \% * * \\
20 \% * *\end{array}$ \\
\hline \multicolumn{4}{|c|}{ Care intensity in hours } \\
\hline $\begin{array}{l}\text { District nursing } \\
\text { Home help } \\
\text { Private nursing } \\
\text { GP } \\
\text { Informal case }\end{array}$ & $\begin{array}{c}3.5(1.5,6.4) \text { per month } \\
4(3.7,4.5) \text { per month } \\
\text { NA } \\
\text { NA } \\
\text { NA }\end{array}$ & $\begin{array}{l}34(29,27) \text { per week } \\
16(12,15) \text { per week } \\
11(9,7) \text { per week } \\
1.5(1,1.4) \text { per week } \\
45(32,40) \text { per week }\end{array}$ & $\begin{array}{c}8(6.5,6.5) \text { per week } \\
10(6,11) \text { per week } \\
\text { NA } \\
1(0.8,1.5) \text { per week } \\
45(32.40) \text { per week }\end{array}$ \\
\hline \multicolumn{4}{|c|}{ Costs per hour in Durch guilders (1990) } \\
\hline $\begin{array}{l}\text { District nursing } \\
\text { Home helf } \\
\text { Private nursing } \\
\text { GP } \\
\text { Informal care }\end{array}$ & $\begin{array}{r}75 \\
36 \\
61 \\
110 \\
12\end{array}$ & $\begin{array}{r}86 \\
46 \\
71 \\
110 \\
12\end{array}$ & $\begin{array}{r}89 \\
42 \\
71 \\
110 \\
12\end{array}$ \\
\hline
\end{tabular}

* Each month $22 \%$ and $10 \%$ respectively of the women receive this care in the initial episode.

* $30 \%$ respectively $20 \%$ of all terminal patients are dying at home, receiving intensive resp. regular home-care. On average this care consists of the hours mentioned per type of care.

$\mathrm{NA}=$ assurned to be zero, because no data were available (see sensitivity analysis).

Table 2(b). Estimates for length, participation and intensity of home care for cervical cancer patients having advanced disease, average values (medians and standards deviations in parentheses)

\begin{tabular}{|c|c|c|c|}
\hline & \multirow[b]{2}{*}{ Intial episode } & \multicolumn{2}{|c|}{ Terminal episode } \\
\hline & & Intensive care & Regular care \\
\hline $\begin{array}{l}\text { Variable } \\
\text { Episode length }\end{array}$ & $\begin{array}{c}\text { Average (median, SD) } \\
10(6,9) \text { months }\end{array}$ & $\begin{array}{l}\text { Average (median, SD) } \\
21(12,21) \text { days }\end{array}$ & $\begin{array}{l}\text { Average (median, SD) } \\
21(12,21) \text { days }\end{array}$ \\
\hline \multicolumn{4}{|c|}{ Proportion of patients receiring home care } \\
\hline $\begin{array}{l}\text { District nursing } \\
\text { Home help }\end{array}$ & $\begin{array}{l}22 \% * \text { each month } \\
10 \% \text { each month }\end{array}$ & $\begin{array}{l}27 \% * * \\
27 \% * *\end{array}$ & $\begin{array}{l}23 \% * * \\
23 \% * *\end{array}$ \\
\hline \multicolumn{4}{|c|}{ Care intensity in hours } \\
\hline $\begin{array}{l}\text { District nursing } \\
\text { Home help } \\
\text { Private nursing } \\
\text { GP } \\
\text { Informal care }\end{array}$ & $\begin{array}{c}3(1.5,3.3) \text { per month } \\
5(4.2,5) \text { per month } \\
\text { NA } \\
\text { NA } \\
\text { NA }\end{array}$ & $\begin{array}{l}29(25,20) \text { per week } \\
20(16,16) \text { per week } \\
19(16,15) \text { per week } \\
1.5(1,1.4) \text { per week } \\
43(30,41) \text { per week }\end{array}$ & $\begin{array}{c}8(6,5.5) \text { per week } \\
10(7,8) \text { per week } \\
\text { NA } \\
1(0.8,1.5) \text { per week } \\
43(30,41) \text { per week }\end{array}$ \\
\hline \multicolumn{4}{|c|}{ Costs per hour in Dutch guilders (1990) } \\
\hline $\begin{array}{l}\text { District nursing } \\
\text { Home help } \\
\text { Private nursing } \\
\text { GP } \\
\text { Informal care }\end{array}$ & $\begin{array}{r}75 \\
36 \\
61 \\
110 \\
12\end{array}$ & $\begin{array}{r}81 \\
47 \\
73 \\
110 \\
12\end{array}$ & $\begin{array}{r}86 \\
42 \\
69 \\
110 \\
12\end{array}$ \\
\hline
\end{tabular}

- Each month $22 \%$ and $10 \%$ respectively of the women receive this care in the initial episode

**27\% respectively $23 \%$ of all terminal patients die at home receiving intensive respectively regular home-care. On average this care consists of the hours mentioned per type of care.

$\mathrm{NA}=$ assumed to be zero. because no data were available (see sensitivity analysis).

\section{Terminal episode, regular home care}

Still a substantial part of the terminally ill patients is dying at home without intensive home care. They are receiving informal care and possibly professional care, but less than the maximum amount of regular care.

Length of episode. This is assumed to be 3 weeks as for intensive home care.

Proportion of women receiving care. The number of women dying at home with regular care follows from the total number of deceased minus the number of patients dying in hospitals and nursing homes and at home with intensive care. At this moment the calculation cannot be carried out exactly. The most recent, national and regional, statistics on the number of women dying in hospitals and nursing homes doesn't yet reflect the influence of the recent regional intensive home care project. Therefore it is not known exactly how many women receiving intensive home care substituted this care for hospital and nursing home care or on the other hand received intensive home care instead of regular home care. For an exact estimation both flows should be analyzed. For the moment we assumed the proportions as mentioned in Table 1 , based on the most recent available information. 
Care intensity. Data on care for patients staying at home in the week before entering IHP and outcomes of the Amsterdam study on district nursing indicate that for this group of patients the average level of care is substantially lower than in cases of intensive home care $[8,9]$. On average patients received $8 \mathrm{hr}$ district nursing, $10 \mathrm{hr}$ home help and $1 \mathrm{hr}$ GP care per week, which is considerably less than in cases of intensive home care, see Table 2(a) and (b). Data concerning private nursing are not available from these studies, not surprisingly as private nursing has only very recently become important in the Netherlands.

The intensity of informal care is also unknown. We assumed it to be $45 \mathrm{hr}$ per week, as we had found for intensive home care. On the one hand it could be argued that these patients require less help because they don't need hospital care. On the other hand it is plausible that they are able to stay at home due to the large availability of informal care.

Costs per hour of care. The costs are almost identical as for intensive home care. Only small differences emerge as a result of a slightly different distribution between care during office hours, evening and night.

\section{Initial episode}

Length of episode. The initial episode lasts on average 20 months for breast cancer and 10 months for cervical cancer; this is calculated as the total period of advanced disease according to the hospital patient files $[6,7]$, minus the terminal episode, 3 weeks (see Table $2 \mathrm{a}$ and $\mathbf{b}$ ).

Proportion of women receiving care. The data about district nursing only allow an estimation of the average proportion of women in the initial episode receiving district nursing care in any month. At any moment during the initial episode $22 \%$ (equal for both diseases) of these women are receiving district nursing care. The average care-intensity per patient is relatively low, $3-3.5 \mathrm{hr}$ per month. In the same way the proportion of women receiving home help is assumed to be $10 \%$ for both diseases.

Care intensity. The intensity of home help for women with advanced cancer is better documented and was estimated as 4 (breast cancer) respectively $5 \mathrm{hr}$ (cervical cancer) per week, which is slightly higher than for the average client receiving home help. No specific information is available for estimating the amount of informal care, private nursing and care of general practitioners, which is a serious shortcoming. With respect to informal care only rough, not disease-specific estimates exist [19] which are not likely to reflect the situation of a patient during the initial episode of advanced cervical cancer.

The average intensity of care during the initial episode turns out to be quite modest compared with the terminal episode, see Tables 2(a) and (b).

Costs per hour of care. The costs per hour for nursing and home help are lower than in the terminal episode, because most care is given during office hours.

\section{Total costs of home care}

Combining the estimates of the four relevant variables for both episodes gives the costs of home care as shown in Table 3. The average costs of home care per patient having advanced breast cancer are just over 8500 guilders, for cervical cancer 7200 guilders. More than half of the total costs are incurred by the intensive home care in the terminal episode. The higher costs for breast cancer are largely caused by greater length of the initial episode: 20 vs 10 months, as the costs of home care per month in the initial episode are approx equal for both disease: dfl 120 .

The district nursing and home help take the lion's share of costs. Informal care takes $10 \%$ of the total costs for both diseases. If reliable data were available about informal care in the initial episode the share of informal care costs could be higher, raising total costs as well, see the sensitivity analysis.

These outcomes can not easily be compared with results from other studies for two reasons: firstly, most studies don't incorporate intensive home care and secondly analyses of costs of home care often don't discern patients having different types of cancer.

\section{Total costs of advanced disease}

Scparate studies on the costs of in hospital care and nursing home care have been carried out in the context of cost-effectiveness analysis on screening for breast and cervical cancer. Total average costs per patient having advanced disease range from $\mathrm{dfl}$

Table 3. Average costs for home care per patient with advanced breast and cervical cancer. Costs per type of care and episode in Dutch guilders (1990). Informal care also shown in hours

\begin{tabular}{rlll}
\hline & \multicolumn{2}{c}{ Termitial } \\
& episode & Intensive Regular & Total \\
\end{tabular}

\begin{tabular}{|c|c|c|c|c|}
\hline \multicolumn{5}{|l|}{ Breast cancer } \\
\hline \multicolumn{5}{|l|}{ Type of care } \\
\hline $\begin{array}{l}\text { District nursing } \\
\text { Home help } \\
\text { Private nursing } \\
\text { GP } \\
\text { Material costs } \\
\text { Total professional care }\end{array}$ & $\begin{array}{l}\text { f } 1150 \\
\text { f } 1270 \\
f \quad 0^{*} \\
f \quad 0^{*}\end{array}$ & $\begin{array}{r}2640 \\
660 \\
700 \\
150\end{array}$ & $\begin{array}{c}430 \\
250 \\
0^{\circ} \\
70\end{array}$ & $\begin{array}{r}4220 \\
2180 \\
700 \\
220 \\
400 \\
7720\end{array}$ \\
\hline $\begin{array}{l}\text { Informal care } \\
\text { Total costs }\end{array}$ & $\begin{array}{l}\text { f } 0^{2} \\
\text { f } 2420\end{array}$ & $\begin{array}{r}490 \\
4640\end{array}$ & $\begin{array}{r}320 \\
1070\end{array}$ & $\begin{array}{r}810 \\
8530\end{array}$ \\
\hline Informal care (hr) & $0^{4}$ & 41 & 27 & 68 \\
\hline \multicolumn{5}{|l|}{ Cercical cancer } \\
\hline \multicolumn{5}{|l|}{ Type of care } \\
\hline $\begin{array}{l}\text { District nursing } \\
\text { Home help } \\
\text { Private nursing } \\
\text { GP } \\
\text { Material costs } \\
\text { Total professional care }\end{array}$ & $\begin{array}{lr}\text { f } & 500 \\
\text { f } & 770 \\
\text { f } & 0^{2} \\
f & 0^{2}\end{array}$ & $\begin{array}{r}1910 \\
760 \\
1120 \\
130 \\
\\
3920\end{array}$ & $\begin{array}{c}480 \\
290 \\
0^{4} \\
80\end{array}$ & $\begin{array}{r}2890 \\
1820 \\
1120 \\
210 \\
400 \\
6440\end{array}$ \\
\hline Informal care & f $\quad 0^{*}$ & 420 & 360 & 780 \\
\hline Total costs & $\mathrm{f} 1270$ & 4340 & 1210 & 7220 \\
\hline Informal care $(\mathrm{hr})$ & $0^{\prime \prime}$ & 35 & 30 & 65 \\
\hline
\end{tabular}

Assumed to be zero because no data were available (see sensitivity analysis). 
42.700 for breast cancer to df 29.000 for cervical cancer $[6,7]$. For both diseases the hospital bill is responsible for the greatest share in total costs. Costs of home care take $20-25 \%$ of the total costs, in spite of the trend towards substituting home care for hospital care which has been incorporated.

\section{Cost-effectiveness of screening}

Using the average costs per patient for treating advanced disease, we can illustrate the influence of screening on the total treatment costs of advanced disease. Screening can prevent deaths of both types of cancer and therefore yields savings in the costs of treating advanced cancer: df 262 million for breast cancer and 47 million for cervical cancer, see Table 4 .

The cost-effectiveness of screening vs no screening can be expressed in the costs per life-year gained: $\mathrm{dfl}$ 7500 in case of breast cancer and more than df 21,600 for cervical cancer, see Table $4[18,20]$.

The costs of home care take one fifth of the total costs of advanced disease for breast cancer and one fourth for cervical cancer. Ignoring these costs would lead to underestimation of the costs savings in treatment of advanced cancer as a result of screening. Consequently the costs of screening per life-year gained would be overestimated by $5 \%$ (cervical cancer) to $10 \%$ (breast cancer).

\section{SENSITIVITY ANALYSIS}

Sensitivity analysis was done regarding the proportion of women receiving district nursing care and home help in the initial episode. Halving the proportion of patients receiving district nursing care in the initial episode results in dfl 7955 for the costs

Table 4. Costs, effects and cost-effectiveness of screening breast cancer and cervical cancer; compared with no screening

\begin{tabular}{|c|c|c|c|c|}
\hline & \multicolumn{2}{|c|}{ Breast cancer $^{d}$} & \multicolumn{2}{|c|}{ Cervical cancer ${ }^{b}$} \\
\hline & Screening & $\begin{array}{l}\text { No } \\
\text { screening }\end{array}$ & Screening & $\begin{array}{c}\text { No } \\
\text { screening }\end{array}$ \\
\hline \multicolumn{5}{|l|}{$\operatorname{Cos} 15$} \\
\hline Screening & 599 & - & 325 & - \\
\hline $\begin{array}{l}\text { Assessment and } \\
\text { pr. treatment }\end{array}$ & 4384 & 4261 & 231 & 223 \\
\hline $\begin{array}{l}\text { Advanced disease } \\
\text { Hospital care } \\
\text { Home care }\end{array}$ & $\begin{array}{r}2506 \\
626\end{array}$ & $\begin{array}{r}2715 \\
679\end{array}$ & $\begin{array}{r}128 \\
30\end{array}$ & $\begin{array}{r}166 \\
39\end{array}$ \\
\hline $\begin{array}{l}\text { Total costs } \\
\text { Incremental costs }\end{array}$ & $\begin{array}{r}8115 \\
460\end{array}$ & $\begin{array}{c}7655 \\
-\end{array}$ & $\begin{array}{l}714 \\
286\end{array}$ & 428 \\
\hline \multicolumn{5}{|l|}{ Effectireness } \\
\hline $\begin{array}{l}\text { Life-yeurs gained } \\
\text { Cost-effectiteness }\end{array}$ & 61,000 & & 13.300 & - \\
\hline $\begin{array}{l}\text { Costs per life-year } \\
\text { gained }(\times 1000 \mathrm{df})\end{array}$ & 7500 & - & 21.600 & \\
\hline
\end{tabular}

'Source: de Koning et al. 1991:

${ }^{b}$ Source: Koopmanschap el al., 1990

Costs in millions of guilders (1990). Discount rate $5 \%$ per year. Screening policies: breast cancer age $50-70$, interval 2 years; cervical cancer age 37-73. interval 6 years. Screening during 19902017. of home care in case of breast cancer, a decline of $7 \%$. For cervical cancer total costs become dfl 6900 $(-3 \%)$. Our estimate of the proportion of women receiving home help was quite conservative. Doubling this proportion makes the total costs for breast cancer df $9800(+15 \%)$ and for cervical cancer $\mathrm{df}$ $7850(+11 \%)$. Quite dramatic changes in these assumptions don't cause great differences in the total costs for the advanced stage of both diseases.

Valuing informal care is not an undisputed issue. If only costs of professional care are taken into account the average costs of home care per patient become dfl 7720 for breast cancer $(-9 \%)$ and $\mathrm{d} f \mathrm{l}$ 6440 for cervical cancer $(-11 \%)$.

The amount of care in the initial episode provided by private nursing, general practitioners and informal care was assumed to be zero, due to lack of data, which is quite unsatisfactory. If we impute conservative guesses of the amount of care (1 hr per month private nursing and GP-care and $10 \mathrm{hr}$ per week informal care for both diseases) the costs of homc care are the following: $\mathrm{dfl} 10,320$ for breast cancer, an increase of $21 \%$ and df 8115 in case of cervical cancer $(+12 \%)$. For breast cancer this results in a substantial increase in costs.

We also lack a sound empirical basis for the amount of private nursing for terminal patients who receive only regular care. Assuming $5 \mathrm{hr}$ care per week results in only a minor change in results, a $3 \%$ increase in costs of home care for both diseases.

\section{DISCLSSION AND CONCLUSIONS}

Reliable data on home care with respect to advanced cancer patients are very scarce, both in the Netherlands and in other countries. Available information mostly concerns care in the terminal episode of advanced disease. Although the lion's share of home care costs is incurred during the terminal episode, home care in the initial episode is documented less completely, making further research necessary. This research should preferably include monitoring of hospital and home care for individual women from the moment of detection of metastases until death, including daily registration of informal care.

Because in the study period intensive home care was only recently introduced, we were not able to calculate the exact consequences of a nationwide implementation of intensive home care for the proportions of women dying in the hospital. nursing home or at home receiving intensive or regular care. Further analysis of the exact extent of substitution between intramural care and intensive home care and on the other hand substitution between regular home care and intensive home care is necessary.

Despite these data problems, this analysis provides an adequate indication of the magnitude of the costs of home care for these diseases. The average costs of home care per patient range from df 7200 in case of 
cervical cancer to df 8500 for breast cancer. More than half of these costs is incurred in the last month before death. These costs make up $20-25 \%$ of the total costs per patient with advanced disease.

The data clearly show that the average costs of home care per patient for advanced cancer do not vary much between breast and cervical cancer. The costs of home carc in the terminal episode are almost equal for both diseases (dfl 5700 vs 5500) and don't diverge from the costs of other types of advanced cancer in women. The higher costs of home care in the initial episode for breast cancer (dfl 2400) compared with cervical cancer (df 1300) are caused by the different length of advanced disease. The average costs of home care per month during the initial episode are equal for both diseases (df 120).

The costs of home care in advanced disease turn out to be important and influence the cost-effectiveness of screening for these diseases. Some uncertainty remains with respect to the degree of precision of our cost estimates of home care, but it does not influence the cost-effectiveness of screening substantially.

Acknowledgements-We thank H. J. de Koning, M.D., M. van Ballegooijen, M.D. and Professor F. F. H. Rutten, Ph.D. for their helpful and critical comments on earlier versions of this article.

\section{REFERENCES}

1. Miltenburg Th., Mensink J. and Tunissen C. Data on care for cancer patients in the home care experiments May-December 1988 (in Dutch). Institute for Applied Social Sciences, Nijmegen, 1989.

2. Long S. H., Gibbs J. O., Crozier J. P., Cooper D. I., Newman J. F. and Larsen A. M. Medical expenditures of terminal cancer patients during the last year of life Inquiry 21, 315-327, 1984.

3. McCall N. Utilization and costs of medicare services by beneficiaries in their last year of life. Med. Care 22, 329-342, 1984.

4. Spector W. D. and Mor V. Utilization and charges for terminal cancer patients in Rhode Island. Inquiry 21, 328-337, 1984.

5. Baker M. S., Kessler L. G. and Smucker R. C. Sitespecific treatment costs for cancer: an analysis of the medicare continuous history sample file. In Cancer Cost
Issues. Health Administration Press Perspectives. (Edited by Scheffer R. M. and Andrews N. C.), pp. 127-138. Ann Arbor, Michigan, 1989.

6. Koning H. J. de. Ineveld B. M. van, Haes J. C. J. M. de. Oortmarssen G. J. van, Klijn J. G. M. and Maas P. $J$. van der. Advanced breast cancer and its prevention by screening. $B r . J$. Cancer In press.

7. Ballegooijen M. van, Koopmanschap M. A., Subandono $A$. and Oortmarssen G. J. van. Care and costs for advanced cervical cancer. Eur. J. Cancer In press.

8. Lapré F. and van den Bos G. Evening- and night-care by district nursing in Amsterdam. Report of the Amsterdam association of district nursing (in Dutch). Amsterdam, 1987

9. Knapen M., Mensink J. and Ramakers C. Home care experiments, final report period Scptember 1987-May 1988 (in Dutch), Institute for applied social sciences, Nijmegen, 1988.

10. Central Council of Home help. Information bulletin nr. 28; Data concerning volume and costs of home help in June 1988 (in Dutch). Driebergen-Rijsenburg. 1988.

1I. Humanitas (home help agency). Data concerning home help for women having advanced cancer, 1987-1989. Amsterdam, 1990.

12. Miltenburg Th., Zwan H. van der and Hoorn R. van. Prices of home care (in Dutch). Institute for applied social sciences, Nijmegen, 1989.

13. National Association of General Practitioners. Personal communication, 1990.

14. National District Nursing Association. Data on district nursing for women with cancer, sample project 1986 , [987, 1988. Bunnik, 1989.

15. Wright $K$. The economics of informal care of the elderly. Centre for health economics, University of York, discussion paper 23, York, 1987.

16. Hartunian N., Smart N. and Thompson M. The Incidence and Economic Costs of Major Health Impairments. Lexington Books, Lexington, 1981.

17. Riley G., Lubitz J., Prihoda R. and Rabey E. The use and costs of Medicare services by cause of death. Inquiry 24, $233244,1987$.

18. Koning H. J. de, Ineveld B. M. van, Oortmarssen G. J. van, Haes J. C. J. M. de, Collette H. J. A., Hendriks J. H. C. L. and Maas P. J van der. Breast cancer screening and cost-effectiveness: policy alternatives, quality of life considerations and the possible impact of uncertain factors. Int. J. Cancer 49, 531-537. 1991.

19. Tjadens $\mathrm{F}$, and Woldringh $\mathrm{Cl}$. Informal care in the Netherlands (in Dutch). Institute for Applied Social Sciences, Nijmegen, 1989.

20. Koopmanschap M. A., Lubbe J. Th. N., Oortmarssen G. J. van, Agt H. M. E. van, Ballegooijen M. van and Habbema J. D. F. Economic aspects of cervical cancer screening. Soc. Sci. Med. 30, 1081-1087, 1990. 